\title{
Gender differences in response to cold pressor test assessed with velocity-encoded cine-MR imaging of the coronary sinus
}

\author{
Alexis Jacquier*, Antonin Flavian, Frank Kober, Francesca Carta, Boris Maurel, Patrick J Cozzone, Monique Bernard \\ From 2011 SCMR/Euro CMR Joint Scientific Sessions \\ Nice, France. 3-6 February 2011
}

\section{Introduction}

Gender-specific differences in cardiovascular risk are well known, and current evidence supports an existing role of coronary endothelium function in these differences.

\section{Purpose}

To assess non invasively coronary endothelial function in male and female young volunteers by myocardial blood flow (MBF) measurement using coronary sinus (CS) flow quantification by velocity encoded cine MRI at rest and during cold pressor test $(\mathrm{CPT})$.

\section{Methods}

Twenty-four healthy volunteers (12 men, 12 women) underwent MRI in a 3 Tesla scanner (Verio, Siemens, Erlangen, Germany). CPT was performed by immersing the right ankle in ice-water during $4 \mathrm{~min}$. Heart rate and blood pressure were monitored throught the protocol. Coronary sinus flow was measured at rest and during CPT using a non breath-hold velocity encoded phase contrast cine MRI (TR/TE: $45 \mathrm{~ms} / 2 \mathrm{~ms}$, slice thickness:5.5mm, FOV: $250^{2}$, averages: 11 , matrix: $256^{2}$, flow encoding $70 \mathrm{~cm} / \mathrm{s}$, flip angle: $25^{\circ}$, acquisition time: $4 \mathrm{~min}$, GRAPPA $\mathrm{k}$-space reduction factor:4). Left ventricular volumes, function and morphology were evaluated using SSFP sequence. MBF was calculated combining coronary sinus flow quantification and morphologic data using Argus work station (Siemens, Erlangen, Germany). Coronary endothelial function was assessed by comparing MBF at rest and during CPT. Coronary vascular resistance (CVR), rate pressure product and endothelium-dependent vasodilatation index (EDVI) were calculated.

\footnotetext{
CHU La Timone, CEMEREM, Marseille, France
}

\section{Results}

At baseline, MBF was $0.63 \pm 0.23 \mathrm{~mL} \cdot \mathrm{g}^{-1} \cdot \mathrm{min}^{-1}$ in men and $0.79 \pm 0.21 \mathrm{~mL} \cdot \mathrm{g}^{-1} \cdot \mathrm{min}^{-1}$ in women $(\mathrm{P}=\mathrm{ns})$ (figure 1 ). During CPT, the rate pressure product in men significantly increased by $49 \pm 36 \%(\mathrm{p}<0.0001)$ and in women by $52 \pm 22 \%(\mathrm{p}<0.0001)$. MBF increased significantly in both men and women by $0.22 \pm 0.19 \mathrm{~mL} \cdot \mathrm{g}^{-1} \cdot \mathrm{min}^{-1}$ $(\mathrm{p}=0.0022)$ and by $0.73 \pm 0.43 \mathrm{~mL} \cdot \mathrm{g}^{-1} \cdot \mathrm{min}^{-1}(\mathrm{p}=0.0001)$, respectively. The increase in MBF was significantly higher in women than in men $(\mathrm{p}=0.0012)$

\section{Conclusions}

MRI coronary sinus flow quantification for measuring myocardial blood flow revealed a higher response of $\mathrm{MBF}$ to $\mathrm{CPT}$ in women than in men. This finding may reflect gender differences in endothelial-dependent

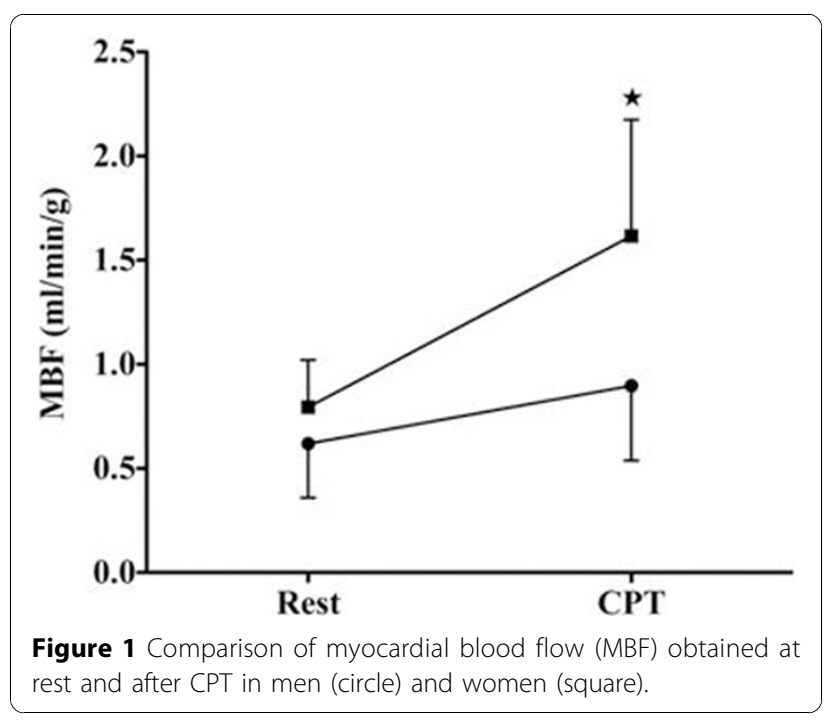

(c) 2011 Jacquier et al; licensee BioMed Central Ltd. This is an open access article distributed under the terms of the Creative Commons B. Wed Central Attribution License (http://creativecommons.org/licenses/by/2.0), which permits unrestricted use, distribution, and reproduction in any medium, provided the original work is properly cited. 
vasodilatation. This non invasive rest/stress protocol may become helpful to study endothelial function in normal physiology and in physiopathology.

Published: 2 February 2011

doi:10.1186/1532-429X-13-S1-P346

Cite this article as: Jacquier et al:: Gender differences in response to

cold pressor test assessed with velocity-encoded cine-MR imaging of

the coronary sinus. Journal of Cardiovascular Magnetic Resonance 2011

13(Suppl 1):P346.

Submit your next manuscript to BioMed Central and take full advantage of:

- Convenient online submission

- Thorough peer review

- No space constraints or color figure charges

- Immediate publication on acceptance

- Inclusion in PubMed, CAS, Scopus and Google Scholar

- Research which is freely available for redistribution 